EGU21-161

https://doi.org/10.5194/egusphere-egu21-161

EGU General Assembly 2021

(c) Author(s) 2021. This work is distributed under

the Creative Commons Attribution 4.0 License.

\title{
Strengths and limitations of sediment source fingerprinting in high mountain environments and relevance for soil restoration
}

\author{
Amaury Frank $\mathbf{I}^{1,2}$, Olivier Evrard ${ }^{3}$, Erik Cammeraat ${ }^{4}$, and Alexia Stokes ${ }^{1}$ \\ ${ }^{1}$ INRAE, AMAP, IRD, CIRAD, CNRS, University Montpellier, Bld de la Lironde, 34398, Montpellier cedex 5, France \\ (amaury.frankl@cirad.fr) \\ ${ }^{2}$ Ghent University, Department of Geography, Krijgslaan 281 (S8), 9000, Ghent, Belgium \\ ${ }^{3}$ Laboratoire des Sciences du Climat et de l'Environnement (LSCE/IPSL), Unité Mixte de Recherche 8212 (CEA/CNRS/UVSQ), \\ Université Paris-Saclay, 91191 Gif-sur-Yvette Cedex, France \\ ${ }^{4}$ Institute for Biodiversity and Ecosystem Dynamics, University of Amsterdam, P.O. Box 94240, 1090 GE Amsterdam, the \\ Netherlands
}

High mountain environments are among the most sensitive on Earth. Due to anthropogenic disturbances and climate change, rates of regolith mobilization due to for example landsliding have been accelerating recently. As a result, soils degrade, geohazards occur and flash floods have negative consequences in downstream areas. The restoration of soils in high mountain environments and an improved understanding of nature-based solutions to land degradation is, therefore, urgent. As finding the origin of erosion sources is a first step to improve mitigation strategies and guide the implementation of effective soil restoration measures, we discuss sediment source fingerprinting research in the context of soil restoration in high mountain environments. A literature review was done based on articles that apply sediment source fingerprinting in high mountain environments and additional articles on land use-based markers and soil restoration were used to develop an outlook for future research. The application of sediment provenance studies in high mountains environments has been limited so far. While some studies yield a rough distinction between sediment sources based on environmental radionuclides or elemental geochemistry, they cannot reflect multiple semi-natural vegetation types which are relevant source types that should be discriminated in high mountain environments. Therefore, we explore emerging techniques such as eDNA tracing that could potentially refine the information on the provenance of sediment based on land use and cover sources. Then, we will address the challenging hydro-geomorphic environment of high mountains and the implications for designing properly a sediment tracing study in such a context. We will conclude by presenting an outlook to guide future applications of sediment source fingerprinting in high mountain environments, where geohazards are imminent and soil restoration is urgent.

Key words: alpine, environmental DNA, erosion, landslide, vegetation 